\title{
3. И. ХИСАМОВА ${ }^{1}$
}

${ }_{1}^{1}$ Краснодарский университет Министерства внутренних дел Российской Федераиии, г. Краснодар, Россия

\section{КОНЦЕПЦИЯ ЦИФРОВЫХ ВААЮТ ЦЕНТРААЬНЫХ БАНКОВ: ОСНОВНЫЕ РИСКИ В ЧАСТИ СОБЛЮАЕНИЯ ТРЕБОВАНИЙ АML ("ПРОТИВОАЕЙСТВИЯ ОТМЫВАНИЮ АЕНЕГ») И КҮС ("ЗНАЙ СВОЕГО КАИЕНТА")}

\author{
Хисамова Зарина Илдузовна, кандидат юридических наук, начальник отделения \\ планирования и координации научной деятельности научно-исследовательского отдела, \\ Краснодарский университет Министерства внутренних дел Российской Федерации \\ Адрес: г. Краснодар, ул. Ярославская, 128, тел.: +7 (861) 258-47-67 \\ E-mail: alise89@inbox.ru \\ ORCID: https://orcid.org/0000-0003-0561-8718 \\ Web of Science Researcher ID: http:/www.researcherid.com/rid/AAL-4093-2020 \\ Scopus Author ID: 57205296970 \\ eLIBRARY ID: SPIN-код: 8152-4380, AuthorID: 727500
}

Цель: исследование нового финансового инструмента, такого как цифровые валюты центральных банков, анализ сущности стейблкоинов как нового финансового инструмента и оценка рисков несоблюдения требований AML («противодействия отмыванию денег») и КҮС («знай своего клиента») при их распространении.

Методы: в ходе исследования применялись методы системного анализа, диалектический и его производные, методы и принципы детерминизма, индукции, дедукции и гипотезы. Для систематизации полученных данных использовались функциональный и статистический методы.

Результаты: цифровые валюты, несмотря на неприятие со стороны многих государств, получают все большее распространение. В этой связи концепция создания государственных цифровых валют является наиболее обсуждаемой в мировом финансовом сообществе. В отдельных странах центральными банками уже сегодня проводится их апробация. Однако их глобальному распространению препятствуют опасения о возможности их использования в преступных целях. В Российской Федерации, где на сегодняшний день не сложилась государственная позиция о природе цифровых финансовых активов, одновременно ведутся дискуссии о возможности создания межгосударственной цифровой валюты. В статье рассматриваются особенности и виды стейблкоинов и их преимущества относительно иных видов криптовалют. Рассмотрены основные преимущества цифровой валюты центрального банка, возможности ее применения в расчетах. По результатам исследования были уточнены основные риски, которые несет в себе распространение государственных цифровых валют.

Научная новизна: в исследовании впервые в российской юридической науке дана оценка концепции цифровых валют центральных банков с позиции ключевых рисков, препятствующих их повсеместному распространению и внедрению. Определены основные риски в области противодействия отмыванию преступных доходов и соблюдению принципа КYC, предполагающего установление конечного бенефициара.

Практическая значимость: приведенные в работе результаты исследования могут быть использованы при совершенствовании государственной политики по легализации цифровых финансовых активов, в том числе государственных цифровых валют.

Ключевые слова: цифровая экономика; правовое регулирование; национальная криптовалюта; блокчейн; система независимых платежей; криптоактивы CBDC; технология распределенных реестров; AML («противодействия отмыванию денег»); KYС («знай своего клиента»)

Конфликт интересов: автором не заявлен.

Как цитировать статью: Хисамова 3. И. Концепция цифровых валют центральных банков: основные риски в части соблюдения требований AML («противодействия отмыванию денег») и KYC («знай своего клиента») // Актуальные проблемы экономики и права. 2020. T. 14, № 3. C. 508-515. DOI: http://dx.doi.org/10.21202/1993-047X.14.2020.3.508-515

Хисамова 3. И. Кониепџия цифровых валют цеентральных банков: основные риски в части соблюдения требований АМL и КҮС Khisamova Z. I. Concept of digital currencies of Central Banks: main risks in observing the requirements of AML and KYC 


\title{
Z. I. KHISAMOVA ${ }^{1}$ \\ ${ }^{1}$ Krasnodar University of the Russian Ministry of Internal Affairs, Krasnodar, Russia \\ CONCEPT OF DIGITAL CURRENCIES OF CENTRAL BANKS: MAIN RISKS IN OBSERVING THE REQUIREMENTS OF AML (“ANTI-MONEY LAUNDERING”) AND KYC (“KNOW YOUR CLIENT”)
}

\author{
Zarina I. Khisamova, PhD (Law), Head of the Department of Research Planning and \\ Coordination, Krasnodar University of the Russian Ministry of Internal Affairs \\ Address: 128 Yaroslavskaya Str., Krasnodar, tel.: +7 (861) 258-47-67 \\ E-mail: alise89@inbox.ru \\ ORCID: https://orcid.org/0000-0003-0561-8718 \\ Web of Science Researcher ID: http://www.researcherid.com/rid/AAL-4093-2020 \\ Scopus Author ID: 57205296970 \\ eLIBRARY ID: SPIN-код: 8152-4380, AuthorID: 727500
}

Objective: to research a new financial tool, namely, digital currencies of central banks, to analyze the essence of stablecoins as a new financial tool, and to assess the risks of non-compliance with the AML ("anti-money laundering") and KYC ("know your customer") requirements when stablecoins are distributed.

Methods: the research used methods of system analysis, dialectical method and its derivatives, methods and principles of determinism, induction, deduction and hypothesis. Functional and statistical methods were used to systematize the obtained data.

Results: digital currencies, though rejected by many states, are becoming more and more widely spread. In this regard, the concept of creating state-owned digital currencies is the most discussed one in the global financial community. In some countries, central banks are already testing them. However, their global spread has been impeded by concerns about the possibility of their use for criminal purposes. In the Russian Federation, where the state has currently no established position on the nature of digital financial assets, discussions are also underway on the possibility of creating an interstate digital currency. The article discusses the features and types of stablecoins and their advantages relative to other types of cryptocurrencies. The main advantages of the Central Bank's digital currency and its application in accounting are considered. According to the study results, the main risks associated with the spread of state digital currencies were clarified.

Scientific novelty: for the first time in the Russian legal science, the study evaluates the concept of digital currencies of central banks from the position of key risks that prevent their widespread distribution and implementation. The main risks in the field of countering money laundering and compliance with the KYC principle, which assumes the final beneficiary identification, are shown.

Practical significance: the research results presented in the paper can be used to improve the state policy on the legalization of digital financial assets, including state digital currencies.

Keywords: Digital economy; Legal regulation; National cryptocurrency; Blockchain; Independent payment system; CBDC crypto assets; Blockchain technology; AML (“anti-money laundering”); KYC ("know your customer”)

Conflict of Interest: No conflict of interest is declared by the author.

For citation: Khisamova Z. I. Concept of digital currencies of Central Banks: main risks in observing the requirements of AML ("Anti-Money Laundering") and KYC ("Know Your Client"), Actual Problems of Economics and Law, 2020, Vol. 14, No. 3, pp. 508-515 (in Russ.). DOI: http://dx.doi.org/10.21202/1993-047X.14.2020.3.508-515

\section{Введение}

Открытые цифровизацией практически безграничные возможности в финансовой сфере активно трансформируют не только финансовые институты и инструменты, но и ведут к качественному пересмотру существующих взаимоотношений в финансовой сфере. Внедрение цифровых институтов и альтернативных, основанных на технологии «блокчейн» 
систем межгосударственных расчетов способно ознаменовать новый этап в развитии международной финансовой системы.

Отдельно стоит отметить и растущую роль транснациональных корпораций и техногигантов, таких как Facebook, которые увидели в новых финансовых инструментах возможность существенно расширить свою сферу влияния на финансовые взаимоотношения пользователей.

Резкая критика со стороны большинства стран Facebook за попытку создания собственной цифровой валюты Libra была снабжена также угрозой санкционной политики в отношении компаний, выступивших в качестве сооснователей Libra: платежных гигантов вроде Visa, MasterCard, Stripe и eBay, что в конечном счете привело к их выходу из проекта ввиду «размытости границ регулирования стейблкоина».

Центробанки заявили, что потенциально огромный охват Facebook трансграничными платежами сделает его системным конкурентом традиционных валют мгновенно. В свою очередь Европейский центральный банк (далее-ЕЦБ) запретил обращение стейблкоинов по типу Libra до момента создания эффективного регуляторного механизма их обращения ${ }^{1}$.

Создание Libra послужило новым толчком в развитии концепции цифровой валюты центрального банка (Central Bank Digital Currency, далее - CBDC). Отдельные страны стали активно вводить запреты на стейблкоины, другие - наоборот, активизировали свои разработки в области создания государственных цифровых валют. В докладе Совета по финансовой стабильности (далее - FSB) для «Большой семерки» (далее $-G 7$ ) отмечается, что глобальные стейблкоины несут угрозу мировой финансовой системе и их запуск невозможен до решения правовых, нормативных и надзорных рисков ${ }^{2}$.

Одновременно крупнейшие финансовые институты, такие как МВФ и Банк международных расчетов,

\footnotetext{
1 ЕС запретили хождение криптовалюты Facebook Libra. URL: https://www.rbc.ru/economics/06/12/2019/5de984cc9a7947 420136eb08 (дата обращения: 20.05.2020).

2 Financial stability board. To G20 Finance Ministers and Central Bank Governors. URL: https://www.fsb.org/wp-content/ uploads/P131019.pdf (дата обращения: 20.05.2020).
}

видят в $C B D C$ «будущее банков» ${ }^{3}$ и «новую веху в истории денег» [1].

В этой связи оценка потенциальных рисков воздействия нового финансового инструмента, такого как стейблкоин, на устоявшиеся социально-экономические отношения представляется как никогда актуальной.

В рамках настоящей статьи предпринята попытка проанализировать сущность стейблкоинов центральных банков как нового финансового инструмента и оценить риски несоблюдения требований $A M L$ ( «противодействия отмыванию денег») и $K Y C$ («знай своего клиента») при их распространении.

\section{Материалы и методы}

Исследование основано на широком спектре международных источников, а также данных международных организаций, национального законодательства и научной литературы. Эмпирическую основу исследования составили глобальные отчеты и официальные документы $G 20, G 7$, Совета по финансовой стабильности, Банка международных расчетов, Евросоюза, Международного валютного фонда, направленные на оценку угроз, исходящих для глобальной экономики от стейблкоинов.

В ходе исследования успешно применялись методы системного анализа, диалектический и его производные, методы и принципы детерминизма, индукции, дедукции и гипотезы. Для систематизации полученных данных применялись методы функциональной и институциональной классификации, статистического анализа, методы ретроспективного, текущего и перспективного анализа и синтеза теоретического и практического материала.

\section{Результаты исследования}

$C B D C$ представляют собой цифровые финансовые активы, выпускаемые центральными банками. Если говорить утрированно, основное отличие $C B D C$ от традиционных фиатных денег состоит в том, что $C B D C$ представляет собой обязательства центрального банка, выраженные в существующих платеж-

\footnotetext{
3 Bank for International Settlements Calls CBDCs a Potential 'Sea Change. URL: https://cointelegraph.com/news/bank-forinternational-settlements-calls-cbdcs-a-potential-sea-change (дата обращения: 20.05.2020).
} 
ных единицах, которые могут служить в качестве средства обмена (расчетов), хранения стоимости и способа оплаты, т. е. выполнять все функции фиата, однако функционируют на основе технологии блокчейн. $C B D C$ представляют собой частный случай стейблкоинов, под которыми понимается цифровой финансовый актив, текущая стоимость которого обеспечена одним из традиционных и ликвидных типов активов - валютой, товарными ценностями, т. е. активами, принятыми в мировой финансовой практике, как надежное и законное средство расчета.

Традиционно принято выделять три разновидности стабильных монет: обеспеченные фиатом или иным ликвидным активом; обеспеченные криптовалютой, где в качестве обеспечительного залога вместо фиата используются токены/коины, и необеспеченные, где номинальная стоимость обеспечивается благодаря работе смарт-контракта [2].

В свою очередь, в отчете ЕЦБ выделяются четыре группы:

- токенизированные коины, которые обеспечены активами, находящимися у эмитента на ответственном хранении;

- стейблкоины с офчейн-обеспечением другими традиционными классами активов;

- стейблкоины, обеспеченные ончейн-активами;

- алгоритмические стейблкоины, обеспеченные работой смарт-контракта.

Привязанные к фиату стейблкоины ЕЦБ описываются как цифровые единицы стоимости, при этом они не являются формой какой-либо конкретной валюты, однако полагаются на некий набор стабилизационных инструментов для минимизации ценовых колебаний. «Токенизированные коины» в классификации ЕЦБ, согласно отчету, - наиболее распространенный вид стейблкоинов, на них приходится почти 97 \% от общего объема торгов. К указанному классу активов относятся и $C B D C$ [3].

Появление стейблкоинов в целом и $C B D C$ в частности обусловлено желанием участников финансового рынка использовать возможности и преимущества, открываемые блокчейном для оказания финансовых услуг, что было ярко продемонстрировано криптовалютами, при этом нивелировав основные недостатки криптовалют, такие как высокая волатильность и анонимность, лишающие их возможности использования в качестве равноценной альтернативы фиату [4].
Напротив, прогнозируемый курс стейблкоинов позволяет производить расчеты даже по долгосрочным контрактам между контрагентами; избежать резкой девальвации коина (в том числе посредством манипуляции инсайдерской информацией на финансовых рынках) и использовать его в качестве равноценной замены фиату ${ }^{4}$.

Большинство проектируемых $C B D C$ предназначены для общего использования, хотя некоторые из них служат исключительно для оптовых платежей и расчетов между центробанками. Применительно к $C B D C$ выделяются три модели доступа для их реализации:

- доступ только финансовых учреждений (Model FI);

- доступ для всей экономики (Model EW);

- доступ для финансовых институтов плюс ограниченный доступ к банкам при поддержке $C B D C$ (Model FI+ $)^{5}$.

Стоит отметить, что цифровая валюта центрального банка не может соответствовать всем канонам криптовалют, таким как децентрализованность, изменение путем голосования, ответвление либо появление новой валюты (форк), свободная купля/продажа.

Концепция $C B D C$ и лежащая в их основе технология $D L T$ на сегодняшний день находится в плоскости спорной дискуссии их воздействия на существующую финансовую систему. С одной стороны, неоспоримы объективные преимущества $C B D C$ на основе $D L T$, которые позволят центральным банкам снизить использование наличных денег, обеспечить доступность системы 24/7, снижение стоимости и сроков транзакции, минимизация издержек и улучшение торговли; для биржи стейблкоины тоже несут несомненную пользу, так как они повышают уровень ее децентрализации и делают падение рынка не таким значимым для инвесторов; наконец, если стейблкоин качественно реализован, он может без проблем заменить американский доллар в расчетах.

${ }^{4}$ European Central Bank. Crypto-Asset Task Force. Cryptoassets: Implications for financial stability, monetary policy and payments and market infrastructures. URL: https://www.ecb.europa. eu/pub/pdf/scpops/ecb.op223 3ce14e986c.en.pdf (дата обращения: 20.05.2020).

5 Цифровая валюта центрального банка. URL: https://cbdc. ru (дата обращения: 20.05.2020). 
И, несомненно, мегарегуляторы всех стран видят указанные преимущества, что подтверждается и их пристальным изучением вопроса запуска $C B D C^{6}$.

Янагава и Ямакоа предполагают, что $C B D C$ может препятствовать спекуляциям с криптовалютами, которые станут менее привлекательными по сравнению с розничными $C B D C$, предлагающими преимущество настоящего платежного инструмента. Некоторые из этих рисков могут быть смягчены за счет выпуска стабильных монет [5]. В свою очередь, иные эксперты считают, что во многих случаях снижение риска носит лишь ограниченный или поверхностный характер [6]. В частности, стабильные монеты с глобальным охватом повышают специфические риски, связанные с ПОД/ФТ, защитой прав потребителей и инвесторов, денежно-кредитной политикой, финансовой стабильностью, конкуренцией и в конечном счете денежным суверенитетом ${ }^{7}$.

Совет по финансовой стабильности высказывает серьезные опасения относительно рисков запуска $C B D C$, в частности, относительно того, насколько фундаментальным окажется воздействие внедрения $C B D C$ на существующую финансовую экосистему, что в результате ставит под сомнение роль банков в финансировании экономической деятельности и делает их повсеместный выпуск маловероятным в краткосрочной перспективе [7]. В феврале 2020 г. председатель Совета заявил, что стейблкоины могут бросить вызов любой финансовой структуре, поэтому страны - участницы $G 20$ должны активно внедрять стандарты FATF в отношении стейблкоинов [8].

В числе ключевых рисков для глобальной финансовой системы в отчете $G 7$ отмечается:

1) расширение круга клиентов (переход от модели взаимодействия с коммерческими банками к многопользовательской аудитории) влечет для центральных банков существенное увеличение операционных рисков;

2) сложности в соблюдении принципов $A M L / K Y C$;

${ }^{6}$ G7: стейблкоины представляют угрозу глобальной финансовой системе. URL: https://forklog.com/g7-stejblkoinypredstavlyayut-ugrozu-globalnoj-finansovoj-sisteme/ (дата обращения: 20.05.2020).

${ }^{7}$ Group of Seven Working Group on Stablecoins (2019). Investigating the impact of global stablecoins, Committee on Payments and Market Infrastructures. URL: https://www.bis.org/ cpmi/publ/d187.htm (дата обращения: 20.05.2020).
3) замена функционала коммерческих банков $(P K O)$ блокчейном, и, как результат, полное падение банковских доходов;

4) сложности в системе кредитования $p 2 p$ (peer-topeer) и определении процентных ставок;

5) сдерживание конкуренции и угрозу финансовой стабильности, если пользователи внезапно утратят доверие к цифровой валюте.

В отдельном письме в адрес министров финансов стран «Большой двадцатки» $(G 20)$ председатель Совета по финансовой стабильности также отметил, что все эти вызовы «должны быть решены в приоритетном порядке» ${ }^{8}$.

14 апреля 2020 г. Совет по финансовой стабильности представил общие рекомендации по регулированию стейблкоинов. Так, стейблкоины должны соответствовать тем же требованиям, которые соблюдаются и другими организациями, несущими в себе аналогичные риски, независимо от применяемых технологий. То есть к стейблкоинам неукоснительно должны применяться процедуры DUE DILIGENCE и $K Y C / A M L$, что позволит хотя бы частично устранить риски. Вместе с тем отмечается, что контроль за межгосударственными стейблкоинами, используемыми для совершения международных платежей, усложняется различиями в финансовом регулировании разных стран. Дискуссии вызывает и контроль за эмиссией и оборотом фиата, к которому привязаны $C B D C$.

Государствам рекомендовано проявить гибкость и разработать единый стандарт регулирования цифровых валют, чтобы их эмитенты не могли «переезжать» из одной юрисдикции в другую. При необходимости уполномоченные органы должны конкретизировать регулирование и устранить возможные пробелы во внутренней правовой системе, чтобы эффективно минимизировать риски, которые представляют международные стейблкоины. Отдельное внимание в рекомендациях уделено операторам стейблкоинов. Операторы стабильных криптовалют в обязательном порядке должны принимать меры для эффективного управления рисками и устойчивой работы своей системы. В частности, они обязаны обеспечить защиту

8 To G20 Finance Ministers and Central Bank Governors. URL: https://www.fsb.org/wp-content/uploads/P131019.pdf (дата обращения: 20.05.2020). 
от кибератак, противодействовать отмыванию денег и финансированию терроризма [8].

Как известно, требования $A M L$ («противодействия отмыванию денег») и $K Y C$ («знай своего клиента») подразумевают обязательное раскрытие информации о транзакциях, превышающих определенную сумму, чтобы избежать их использования в преступных целях. Технология блокчейн в настоящее время достаточно продвинута, чтобы программировать транзакции, делая их конфиденциальными для определенных сторон в сети и по-прежнему оставляя контроль для регулирующих органов. Смарт-контракты помогают автоматизировать раскрытие информации и соблюдение требований способом, который ранее был невозможен.

Стоит остановиться еще на одном отличительном преимуществе $C B D C$, которое в глобальном социально-политическом контексте приобретает характер проблемы. Распространение $C B D C$ способно упорядочить трансграничные платежи и создать беспроблемную торговлю без границ, что в свою очередь означает усиление конкуренции за объемы мировой торговли и, следовательно, повышение суверенитета над глобальной экономикой.

$\mathrm{B}$ то время как большинство розничных $C B D C$ сосредоточены на внутренних экономических вопросах, некоторые проекты направлены на содействие торговым отношениям в конкретном регионе, формируя цифровую альтернативу доллару США 9 .

Примерами таких стейблкоинов являются региональный стейблкоин, поддерживаемый корзиной валют, включая китайский юань, японскую иену, южнокорейский вон и гонконгский доллар ${ }^{10}$, что позволит странам Восточной Азии избавиться от гегемонии доллара США. Однако подкрепление $C B D C$ национальными валютами различных государств создает значительные трудности в обеспечении системы, проведении процедур $K Y C / A M L$, а также определении централизованного эмитента и оператора $C B D C$. Еще

\footnotetext{
9 Regional CBDCs Can Fuel International Trade, but USD Seems Unbeatable. URL: https://cointelegraph.com/news/regionalcbdcs-can-fuel-international-trade-but-usd-seems-unbeatable (дата обращения: 20.05.2020)

${ }^{10}$ URL: https://cointelegraph.com/news/china-consideringeast-asia-regional-cryptocurrency-to-rival-dollar-and-libra (дата обращения: 20.05.2020).
}

один пример региональной $C B D C$ - это цифровое евро $C B D C$. Наиболее активно концепция исследуется французским центральным банком Banque de France ${ }^{11}$.

Одним из главных участников неофициальной гонки $C B D C$ является цифровой юань - цифровая валюта, которая активно развивается Народным банком Китая. По словам представителя китайского центрального банка, «цифровой юань» может быть задействован на таких крупных платежных платформax, как WeChat и Alipay. Безопасность криптовалюты КНР будет подобна той, что предлагают бумажные деньги. При этом актив можно будет использовать без подключения к Интернету [9].

Оспаривание доллара как валюты мировой торговли возможно только в том случае, если базовая валюта указанного $C B D C$ уже является основной валютой мировой торговли. Цифровой юань является одним из немногих $C B D C$-проектов, у которого есть реальная возможность потеснить доллар: из-за торговых отношений и партнеров Китая, которые разбросаны по всему миру, и масштабов мировой торговли, происходящих с Китаем.

Примечательно, что США также рассматривают возможность размещения своей национальной валюты на блокчейн-рельсах, что, если их правильно и быстро реализовать, может полностью остановить многие конкурирующие проекты ${ }^{12}$.

Еще одной альтернативой являлась идея создания наднациональной $C B D C$ БРИКС [10]. В числе ключевых преимуществ такой инициативы видится возможность замены системы SWIFT блокчейн-технологией, которая будет в основе такой цифровой валюты, а также ее меньшая подверженность возможной девальвации в отличие от национальных валют, уже используемых во взаимных торговых расчетах.

Потенциально реализация такого проекта могла бы позволить обеспечить значительную эффективность торговых отношений в рамках группы за счет снижения транзакционных издержек, повышения их надежности и в перспективе полностью изменить

${ }^{11}$ URL: https://cointelegraph.com/news/digital-euro-seesfirst-successful-test-at-the-bank-of-france (дата обращения: 20.05.2020).

${ }^{12}$ URL: https://cointelegraph.com/news/regional-cbdcs-canfuel-international-trade-but-usd-seems-unbeatable (дата обращения: 20.05.2020). 
структуру торговых отношений посредством внедрения технологии «блокчейн» и смарт-контрактов. Особо привлекательной такая идея выглядит на фоне новостей о запуске в тестовом режиме $C B D C$ Bceмирным банком и МВФ для изучения возможностей цифровых активов и блокчейна ${ }^{13}$.

Вместе с тем существуют серьезные сомнения о реальной возможности реализации такой инициативы. В первую очередь ввиду диаметральной противоположности национальных подходов развивающихся стран к регулированию цифровых валют. Следует отметить, что промедление в вопросах создания «единой цифровой среды доверия», основывающейся на межгосударственных соглашениях, на фоне постоянного отдаления национальных подходов стран группы в вопросе регулирования цифровых финансовых активов сводит практически на нет возможность реализации такой инициативы.

Отсутствие на международном уровне единой согласованной позиции относительно юридической природы $C B D C$ и стратегии ее реализации отражается на качестве национального правового регулирования виртуальной валюты [11-12].

Поиск глобального консенсуса и определение стандартов $C B D C$ центральными банками мировых держав является крайне важным для обеспечения будущего цифровых валют и возможности быстрых трансграничных переводов в режиме реального времени.

\section{Выводы}

Цифровые инновации в финансовой сфере способствуют более быстрым, дешевым и более инклюзивным платежам. Преимущества, которые несут в себе $C B D C$, способны существенным образом преобразить экономическую обстановку в мире, снизить существующие издержки и стимулировать рост глобальной экономики благодаря доступу к рынкам широкого круга субъектов. МВФ настаивает на применении $C B D C$ для расширения доступа к финансовым услугам, особенно в бедных странах, где финансовые учреждения не развиты и не всегда доступны ${ }^{14}$.

Вместе с тем такие преимущества могут быть реализованы исключительно при наличии надлежащим образом проработанного и регламентированного порядка внедрения $C B D C$. К ним необходимо применять правила, действующие в традиционной финансовой индустрии. Речь идет о требованиях к платежам и проверке личности клиентов. Это позволит хотя бы частично устранить цифровые риски [13].

Глобальное масштабирование $C B D C$ создает важные проблемы и риски, связанные с финансовой стабильностью, денежно-кредитной политикой, гарантиями недопущения отмывания денег и финансирования терроризма, а также защиты потребителей и инвесторов от рисков. Однако контроль за стейблкоинами, используемыми для совершения международных платежей, усложняется различиями в финансовом регулировании разных стран.

\section{Список литературы}

1. Casting Light on Central Bank Digital Currencies / T. M. Griffoli, M. S. M. Peria, I. Agur et al. // International Monetary Fund, 2018. 39 p.

2. Sidorenko E. L. Stablecoin as a New Financial Instrument // S. Ashmarina, M. Vochozka, V. Mantulenko (eds.). Digital Age: Chances, Challenges and Future. ISCDTE 2019. Lecture Notes in Networks and Systems. 2020. Vol 84. Springer, Cham. DOI: https://doi.org/10.1007/978-3-030-27015-5_75

3. In search for stability in crypto-assets: are stablecoins the solution? / D. Bullmann, J. Klemm, A. Pinna // European Central Bank. 2019. URL: https://www.ecb.europa.eu/pub/pdf/scpops/ecb.op230 d57946be3b.en.pdf (дата обращения: 20.05.2020).

4. Barontini C., Holden H. Proceeding with caution - a survey on central bank digital currency // Bank for International Settlements. 2019. URL: https://www.bis.org/publ/bppdf/bispap101.pdf (дата обращения: 20.05.2020).

5. Yanagawa N., Yamaoka H. Digital Innovation, Data Revolution and Central Bank Digital Currency // Bank of Japan Working Paper Series, 2019. 19-E-2. URL: http://www.boj.or.jp/en/research/wps_rev/wps_2019/data/wp19e02.pdf (дата обращения: 20.05.2020).

\footnotetext{
${ }^{13}$ Всемирный банк и МВФ запустили блокчейн с тестовой криптовалютой «LearningCoin». URL: https://miningcryptocurrency.ru/mvf-sozdal-blokchejn-s-kriptovalyutoj-learningcoin/ (дата обращения: 20.05.2020).
}

\footnotetext{
${ }^{14}$ International Monetary Fund. IMF Financial Operations. URL: https://www.elibrary.imf.org/doc/IMF071/247649781484330876/24764-9781484330876/Other_formats/Source PDF/24764-9781484348826.pdf (дата обращения: 20.05.2020).
} 
6. Berentsen A., Schär F. Stablecoins: The quest for a low volatility cryptocurrency // The Economics of Fintech and Digital Currencies / ed. A. Fatás, A VoxEU.org Book, CEPR Press, 2019. Pp. 65-75.

7. Brummer C. Cryptoassets: Legal, Regulatory, and Monetary Perspectives. Oxford University Press References, 2019.386 p.

8. Jones H., Wilson T. G20 sets ground rules ahead of Facebook's Libra stablecoin // Reuters. 2020. URL: https://www.reuters. com/article/us-g20-regulator-stablecoins/g20-sets-ground-rules-ahead-of-facebooks-libra-stablecoin-idUSKCN21W0TU (дата обращения: 20.05.2020).

9. Лиходей Е. Центробанк Китая: «цифровой юань» будет похож на стейблкоин Libra от Facebook // Bloomchain. 2019. URL: https://bloomchain.ru/newsfeed/tsentrobank-kitaya-tsifrovoj-yuan-budet-pohozh-na-stejblkoin-libra-ot-facebook/ (дата обращения: 20.05.2020).

10. Terenzi C. The First Multinational Cryptocurrency -A Russian Creation? // CoinStaker. 2018. URL: https://www.coinstaker. com/multinational-cryptocurrency-russia-brics-eeu/ (дата обращения: 20.05.2020).

11. Ciaian P., Rajcaniova M. Virtual relationships: Short-and long-run evidence from BitCoin and altcoin markets // Journal of International Financial Markets, Institutions and Money. 2018. № 52. Pp. 173-195.

12. Exploring the Dynamic Relationships between Cryptocurrencies and Other Financial Assets / S. Corbet, A. Meegan, C. Larkin et al. // Economics Letters. 2018. № 165. Pp. 28-34.

13. Artificial Intelligence and Problems of Ensuring Cyber Security / Z. I. Khisamova, I. R. Begishev, E. L. Sidorenko // International Journal of Cyber Criminology. 2019. Vol. 13, № 2. Pp. 564-577.

\section{References}

1. Griffoli T. M., Peria M. S. M., Agur I., Ari A., Kiff J., Popescu A., Rochon C. Casting Light on Central Bank Digital Currencies, International Monetary Fund, 2018. 39 p.

2. Sidorenko E. L. Stablecoin as a New Financial Instrument. In: Ashmarina S., Vochozka M., Mantulenko V. (eds). Digital Age: Chances, Challenges and Future. ISCDTE 2019. Lecture Notes in Networks and Systems, 2020, vol. 84. Springer, Cham. DOI: https://doi.org/10.1007/978-3-030-27015-5 75

3. Bullmann D., Klemm J., Pinna A. In search for stability in crypto-assets: are stablecoins the solution?, European Central Bank, 2019, available at: https://www.ecb.europa.eu/pub/pdf/scpops/ecb.op230 d57946be3b.en.pdf (access date: 20.05.2020).

4. Barontini C., Holden H. Proceeding with caution - a survey on central bank digital currency, Bank for International Settlements, 2019, available at: https://www.bis.org/publ/bppdf/bispap101.pdf (access date: 20.05.2020).

5. Yanagawa N., Yamaoka H. Digital Innovation, Data Revolution and Central Bank Digital Currency, Bank of Japan Working Paper Series, 2019. 19-E-2, available at: http://www.boj.or.jp/en/research/wps_rev/wps_2019/data/wp19e02.pdf (access date: 20.05.2020).

6. Berentsen A., Schär F. Stablecoins: The quest for a low volatility cryptocurrency, In The Economics of Fintech and Digital Currencies, edited by A. Fatás, A VoxEU.org Book, CEPR Press, 2019, pp. 65-75.

7. Brummer C. Cryptoassets: Legal, Regulatory, and Monetary Perspectives, Oxford University Press References, 2019,386 p.

8. Jones H., Wilson T. G20 sets ground rules ahead of Facebook's Libra stablecoin, Reuters, 2020, available at: https://www. reuters.com/article/us-g20-regulator-stablecoins/g20-sets-ground-rules-ahead-of-facebooks-libra-stablecoin-idUSKCN21W0TU (access date: 20.05.2020).

9. Likhodei E. Central Bank of China: "digital yuan" will resemble a Libra stablecoin of Facebook, Bloomchain, 2019, available at: https://bloomchain.ru/newsfeed/tsentrobank-kitaya-tsifrovoj-yuan-budet-pohozh-na-stejblkoin-libra-ot-facebook/ (access date: 20.05.2020) (in Russ.).

10. Terenzi C. The First Multinational Cryptocurrency - A Russian Creation?, CoinStaker, 2018, available at: https://www. coinstaker.com/multinational-cryptocurrency-russia-brics-eeu/ (access date: 20.05.2020).

11. Ciaian P., Rajcaniova M. Virtual relationships: Short-and long-run evidence from BitCoin and altcoin markets, Journal of International Financial Markets, Institutions and Money, 2018, No. 52, pp. 173-195.

12. Corbet S., Meegan A., Larkin C., Lucey B., Yarovaya L. Exploring the Dynamic Relationships between Cryptocurrencies and Other Financial Assets, Economics Letters, 2018, No. 165, pp. 28-34.

13. Khisamova Z. I., Begishev I. R., Sidorenko E. L. Artificial Intelligence and Problems of Ensuring Cyber Security, International Journal of Cyber Criminology, 2019, Vol. 13, No. 2, pp. 564-577.

Дата поступления / Received 08.07.2020

Дата принятия в печать / Accepted 14.08.2020

Дата онлайн-размещения / Available online 25.09.2020

(C) Хисамова 3. И., 2020

(C) Khisamova Z. I., 2020

Хисамова 3. И. Концепция циифровых валют центральных банков: основные риски в части соблюдения требований АМL и КYС Khisamova Z. I. Concept of digital currencies of Central Banks: main risks in observing the requirements of AML and KYC 